\title{
The chemokine CCL18 characterises Pseudomonas infections in cystic fibrosis lung disease
}

\author{
Andreas Hector ${ }^{1,4}$, Carolin Kröner ${ }^{2,4}$, Melanie Carevic ${ }^{1}$, Martina Bakele ${ }^{1}$, \\ Nikolaus Rieber ${ }^{1}$, Joachim Riethmüller ${ }^{1}$, Matthias Griese ${ }^{2}$, Gernot Zissel ${ }^{3}$ \\ and Dominik Hartl ${ }^{1}$
}

Affiliations: 'Dept of Pediatrics I and Interdisciplinary Center for Infectious Diseases, University of Tübingen, Tübingen, Germany. ${ }^{2}$ Dept of Pediatrics, Ludwig-Maximilians-University, Munich, Germany. ${ }^{3}$ Dept of Pneumology, Center for Medicine, Medical Center - University of Freiburg, Freiburg, Germany. ${ }^{4}$ Both authors contributed equally.

Correspondence: Dominik Hartl, Dept of Pediatrics I, University of Tübingen, Hoppe-Seyler-Str. 1, 72076 Tübingen, Germany. E-mail: dominik.hartlamed.uni-tuebingen.de

ABSTRACT Cystic fibrosis (CF) lung disease is characterised by chronic Pseudomonas aeruginosa infection and leukocyte infiltration. Chemokines recruit leukocytes to sites of infection. Gene expression analysis identified the chemokine CCL18 as upregulated in CF leukocytes. We hypothesised that CCL18 characterises infection and inflammation in patients with CF lung disease.

Therefore, we quantified CCL18 protein levels in the serum and airway fluids of CF patients and healthy controls, and studied CCL18 protein production by airway cells ex vivo.

These studies demonstrated that CCL18 levels were increased in the serum and airway fluids from CF patients compared with healthy controls. Within CF patients, CCL18 levels were increased in P. aeruginosainfected CF patients. CCL18 levels in the airways, but not in serum, correlated with severity of pulmonary obstruction in CF. Airway cells isolated from P. aeruginosa-infected CF patients produced significantly higher amounts of CCL18 protein compared with airway cells from CF patients without P. aeruginosa infection or healthy controls.

Collectively, these studies show that CCL18 levels characterise chronic P. aeruginosa infection and pulmonary obstruction in patients with CF. CCL18 may, thus, serve as a potential biomarker and therapeutic target in CF lung disease.

@ERSpublications

CCL18 levels characterise chronic $P$. aeruginosa infection and pulmonary obstruction in patients with CF http://ow.ly/AbVUq

Received: April 142014 | Accepted after revision: June 272014 | First published online: Aug 192014

Support statement: Supported by the German Research Foundation (DFG, Emmy Noether Programme HA 5274/3-1 to D. Hartl) and the Novartis Foundation (D. Hartl).

Conflict of interest: Disclosures can be found alongside the online version of this article at erj.ersjournals.com

Copyright @ERS 2014 


\section{Introduction}

Lung disease determines morbidity and mortality of patients with cystic fibrosis (CF). The combination of bacterial infections, continuous leukocyte recruitment into the airways and tissue remodelling are hallmarks of CF lung disease $[1,2]$. These processes are regulated by chemokines, a family of proteins essential for leukocyte migration, antibacterial host defence, fibrosis, tissue remodelling and angiogenesis [3, 4]. Several chemokines have been linked to the pathogenesis of pulmonary diseases, recently the CC chemokine ligand (CCL)18, formerly known as pulmonary and activation-regulated chemokine (PARC) [5-9]. CCL18 was first described in 1997 and is exclusively present in primates [10]. CCL18 expression is particularly high in the lung, but it is also present, in lower amounts, in lymphoid tissues [10]. At the cellular level, CCL18 is produced by leukocytes, mainly macrophages in response to T-helper cell (Th) type 2 cytokines [11] and, to a lesser extent, dendritic cells [12]. Functionally, CCL18 modulates a variety of immune cells, including T-cells, B-cells, dendritic cells and haematopoietic progenitor cells [9], and stimulates collagen production by lung fibroblasts [13]. CCL18 is readily detectable in normal human serum and was found to be elevated in several systemic diseases $[9,14,15]$, in particular in chronic lung diseases, such as hypersensitivity pneumonitis [16], idiopathic pulmonary fibrosis (IPF) [17], chronic obstructive pulmonary disease (COPD) [18-20], sarcoidosis [21] and allergic asthma [22].

A macroarray gene expression analysis in CF neutrophils, comprising 1050 genes, identified the chemokines CCL17 and CCL18 as specifically upregulated in CF neutrophils [23], suggesting that these chemokines could be involved in the pathogenesis of CF lung disease. The chemokine CCL17 (also known as TARC) has been previously described to be involved in allergic bronchopulmonary aspergillosis (ABPA) [24-26], but the role of CCL18 in CF remained elusive. We hypothesised that CCL18 plays a role in chronic CF lung disease and comprehensively quantified CCL18 protein levels in serum and airway fluids from individuals with CF and control subjects. Our studies demonstrate that CCL18 levels characterise chronic Pseudomonas aeruginosa infections in CF patients and correlate with lung function and CXCR1 chemokines, suggesting CCL18 as a potential biomarker and therapeutic target in CF.

\section{Materials and methods}

Patient cohorts

The CF group included 18 male and 22 female patients with a mean \pm SD age of $21 \pm 14$ years (table 1 ). Inclusion criteria were the diagnosis of CF by clinical symptoms and positive sweat tests (sweat $\mathrm{Cl}^{-}$ concentration $>60 \mathrm{mmol} \cdot \mathrm{L}^{-1}$ ) or disease-causing mutations in the cystic fibrosis transmembrane conductance regulator (CFTR) gene, forced expiratory volume in $1 \mathrm{~s}$ (FEV1) $>30 \%$ predicted and being clinically stable and on steady concomitant therapy at least 4 weeks prior to the study. 18 CF patients were $\Delta$ F508 homozygous, 15 were $\Delta$ F508 heterozygous carriers of the CFTR gene and seven had CFTR mutations

\section{TABLE 1 Patient groups}

\begin{tabular}{|c|c|c|}
\hline & Cystic fibrosis & Controls \\
\hline Subjects & 40 & 27 \\
\hline Age years & $21 \pm 14$ & $25 \pm 9$ \\
\hline Males/females & $18 / 22$ & $12 / 15$ \\
\hline White blood cell count $\times 10^{9} \cdot \mathrm{L}^{-1}$ & $11 \pm 6$ & $8 \pm 3$ \\
\hline FEV1 \% predicted (range) & $66 \pm 14(33-92)$ & \\
\hline Neutrophils in sputa \% & $82 \pm 34$ & $17 \pm 10$ \\
\hline Pseudomonas aeruginosa & 18 & ND \\
\hline Staphylococcus aureus (MSSA) & 10 & ND \\
\hline S. aureus (MRSA) & 1 & ND \\
\hline Haemophilus influenzae & 3 & ND \\
\hline Achromobacter xylosoxidans & 4 & ND \\
\hline Stenotrophomonas maltophilia & 5 & ND \\
\hline Burkholderia cepacia & 1 & ND \\
\hline Aspergillus fumigatus & 14 & ND \\
\hline Candida albicans & 19 & ND \\
\hline Antibiotics & 18 & 0 \\
\hline$\Delta \mathrm{F} 508$ homozygous/heterozygous/other & $18 / 15 / 7$ & ND \\
\hline
\end{tabular}

Results are expressed as $n$ or mean $\pm S D$, unless otherwise stated. FEV1: forced expiratory volume in $1 \mathrm{~s}$; MSSA: methicillin-sensitive S. aureus; MRSA: methicillin-resistant S. aureus; ND: not determined. 
other than $\Delta$ F508. Chronic $P$. aeruginosa infection was defined when $>50 \%$ of patient samples in the year prior to CCL18 analysis were P. aeruginosa positive. According to this definition, 18 CF patients were chronically infected with $P$. aeruginosa. Induced sputum samples were obtained and mechanically processed as described previously $[27,28]$. Other pathogens detected in the CF cohort are listed in table 1. 27 control subjects without pulmonary diseases were selected as the control group ( 12 males, 15 females; mean \pm SD age $25 \pm 9$ years). These subjects had no suspected or proven pulmonary disease and were free of respiratory tract infections. Informed written consent was obtained from all subjects included in the study or their parents, and all study methods were approved by the local ethics committee and by the institutional review board (University of Tübingen, Tübingen, Germany). Induced sputum was obtained, processed and stored as described previously [29]. Cell-free sputum supernatant was stored at $-80^{\circ} \mathrm{C}$ until analysis.

\section{ELISA}

CCL18, CXCL1, CXCL2 and CXCL8 protein levels were measured in duplicates by a commercially available, sandwich ELISA kit (R\&D Systems, Inc., Minneapolis, MN, USA and Creative Biomart, Shirley, NY, USA) according to the manufacturer's instructions. Samples were pre-diluted according to the manufacturer's instructions. The CCL18 intra-assay precision coefficient of variation was $2.6 \%$ and the inter-assay precision coefficient of variation was $8.2 \%$.

\section{CCL18 production}

To quantify CCL18 protein production ex vivo, we isolated sputum cells from CF patients or control subjects using dithiothreitol as described previously [27, 30], followed by centrifugation $(300 \times \mathrm{g})$ and resuspension in RPMI-1640 (Invitrogen, Karlsruhe, Germany) with 10\% heat-inactivated fetal bovine serum (Biochrom AG, Berlin, Germany), $200 \mathrm{U} \cdot \mathrm{mL}^{-1}$ penicillin and $200 \mathrm{mg} \cdot \mathrm{mL}^{-1}$ streptomycin (Invitrogen). The resulting cell suspension was incubated at $1 \times 10^{6}$ cells per well at $37^{\circ} \mathrm{C}$ in $5 \% \mathrm{CO}_{2}$. After overnight culture, cell-free supernatants were harvested for ELISA analyses.

\section{Statistical analysis}

Differences between the patient groups were calculated using the nonparametric Kruskal-Wallis test. When a significant difference was found, the nonparametric Mann-Whitney U-test was applied for two-group comparisons. Correlations were tested using Spearman's rho test. A correlation was assumed when the correlation coefficient was $>0.3$. A p-value $<0.05$ was considered to be significant. Statistical analysis was performed with Prism 4.0 (Graph Pad Software, San Diego, CA, USA) and Stata version 8.2 for Windows (StataCorp., College Station, TX, USA).

\section{Results}

Increased systemic and airway CCL18 protein levels in CF

CCL18 protein levels were significantly increased in both serum (fig. 1a) and sputum supernatants (fig. 1b) from CF patients compared with healthy controls. Within individual CF patients, CCL18 protein levels were consistently higher in serum than in sputum supernatants (fig. 1c). Despite these statistically significant differences between CF patients and healthy control subjects, the detected CCL18 protein levels showed a broad range in both serum and sputum, from levels similar to those found in healthy control subjects up to 30-fold higher serum levels in distinct CF patients compared with healthy control subjects (fig. 1). Based on this heterogeneity, we hypothesised that CCL18 protein levels in CF patients are modulated by CFassociated factors.

\section{CCL18 characterises chronic $\mathrm{P}$. aeruginosa infection in CF}

To dissect the factors that modulate CCL18 levels in CF patients, we correlated systemic and airway CCL18 protein levels with disease parameters, including age, sex, body mass index, CFTR mutation and medications as well as bacterial and fungal infections. Among all the factors analysed, only P. aeruginosa showed a statistically significant association with CCL18 protein levels. CF patients with chronic $P$. aeruginosa infections had increased CCL18 protein levels in serum (fig. 2a) and sputum supernatants (fig. 2b) compared with patients without chronic $P$. aeruginosa infections. This association was restricted to $P$. aeruginosa and was not a common reflection of underlying infection, since no statistically significant correlations were found between CCL18 protein levels and any other CF-characteristic pathogens, such as Staphylococcus aureus ( $\mathrm{p}>0.05)$, Haemophilus influenzae ( $\mathrm{p}>0.05)$, or Aspergillus fumigatus $(\mathrm{p}>0.05)$ (table 2).

To test whether CF airway cells autonomously produce enhanced levels of CCL18 protein, we isolated airway (sputum) leukocytes from healthy control subjects and CF patients and quantified the spontaneous CCL18 protein production capacity ex vivo. These studies demonstrated that CF airway cells produced increased amounts of CCL18 protein compared with healthy control cells (fig. 3a). Moreover, airway cells 

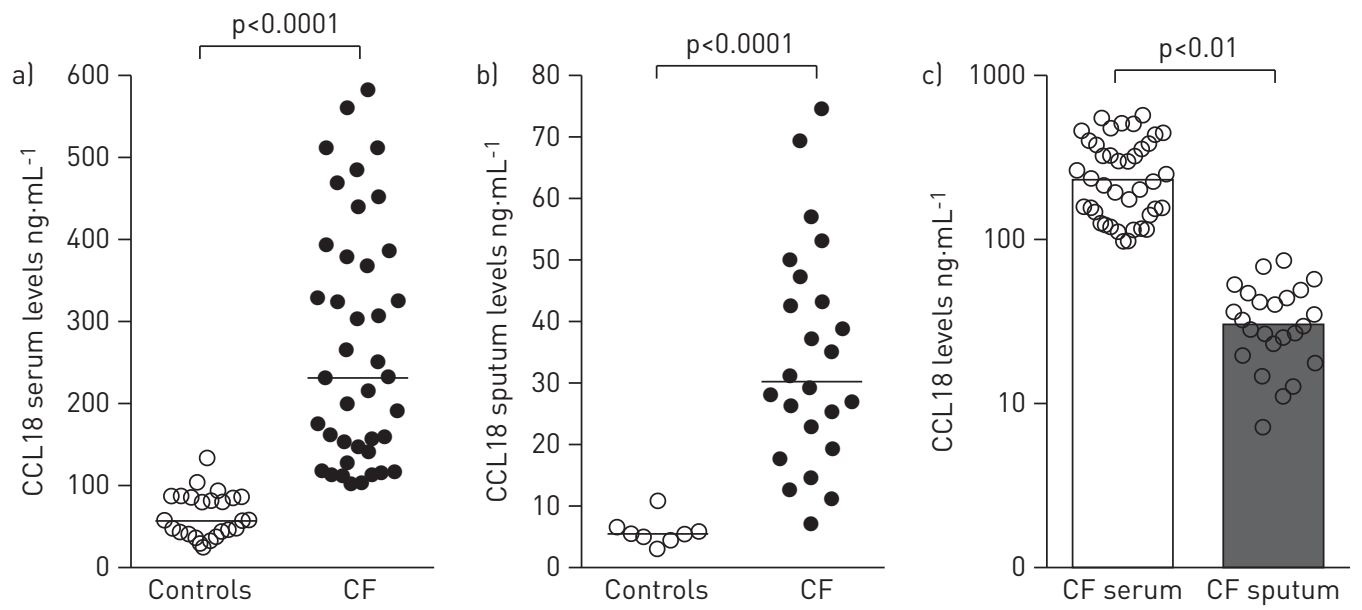

FIGURE 1 CCL18 levels in cystic fibrosis (CF) patients and healthy controls. CCL18 protein levels were quantified by means of ELISA in a) serum and b) sputum from CF patients and healthy control subjects. The scatter graph depicts individual patients with horizontal bars indicating the median for each group. c) Comparison of serum and sputum CCL18 levels in CF patients.

from chronic $P$. aeruginosa-infected CF patients produced significantly higher amounts of CCL18 protein compared with non- $P$. aeruginosa-infected CF patients (fig. $3 b$ ).

\section{CCL18 airway levels correlate with lung function, cell recruitment and CXCR1 chemokines in CF}

CCL18 protein levels in airway fluids were inversely correlated with lung function parameters (FEV1) (fig. 4a), whereas circulating serum CCL18 levels did not show any correlation with FEV1 ( $\mathrm{p}>0.05)$. CCL18 protein levels in sputum further positively correlated with numbers of airway neutrophils $(r=0.64 ; p<0.01)$ and lymphocytes $(\mathrm{r}=0.52 ; \mathrm{p}<0.05)$ in $\mathrm{CF}$ sputa, but not with airway macrophages $(\mathrm{p}>0.05)$. CCL18 levels in serum did not show any correlation with peripheral blood cell counts (data not shown). Inspired by these correlations between airway CCL18 protein levels and numbers of neutrophils infiltrating the airway, we asked whether CCL18 levels correlate with neutrophil-attracting chemokines. Therefore, we quantified protein levels of CXCR1 and CXCR2 chemokines, as they represent the major neutrophil-recruiting chemokine axis, and found that airway levels of the CXCR1 ligand CXCL8 (or interleukin (IL)-8) showed a strong and statistically significant positive correlation with airway protein levels of CCL18 (fig. 4b). By contrast, airway protein levels of the CXCR2 ligands CXCL1 ( $p>0.05)$ and CXCL2 ( $p>0.05)$ did not show a
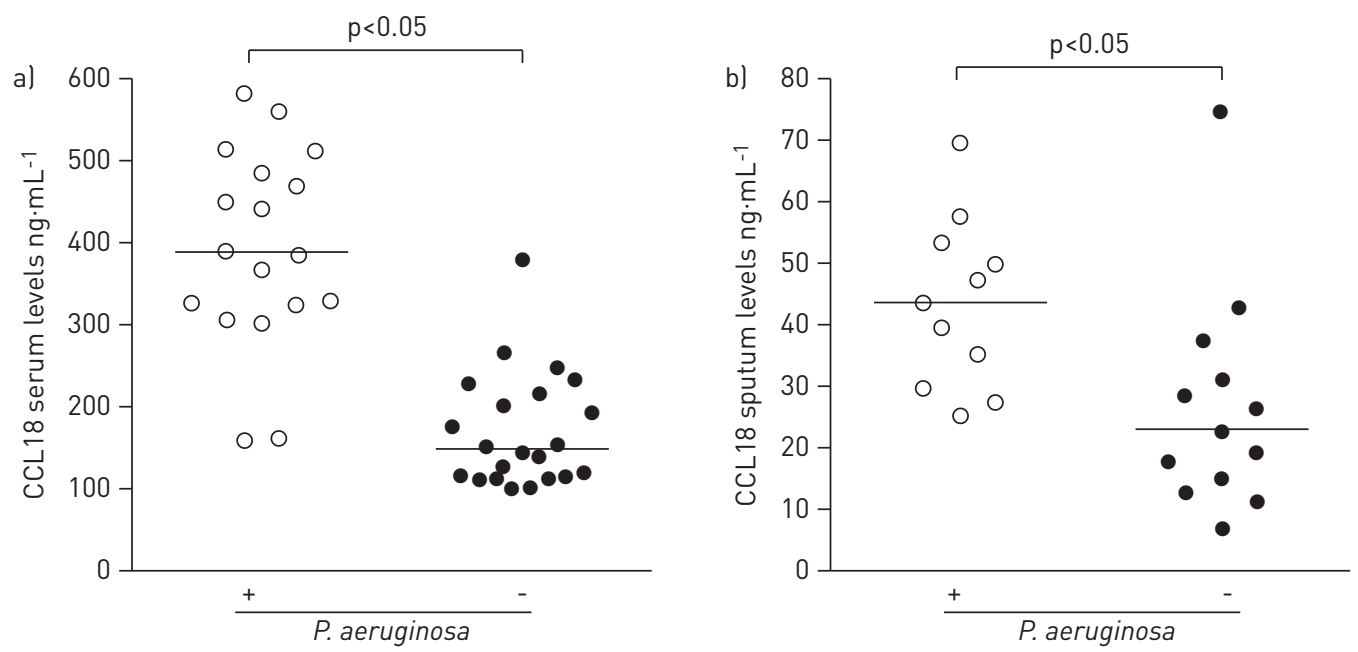

FIGURE 2 CCL18 levels and Pseudomonas aeruginosa infection in cystic fibrosis (CF) patients. CCL18 protein levels were quantified by means of ELISA in a) serum and b) sputum from CF patients with (+) or without (-) chronic P. aeruginosa infection. CF patients were stratified according to chronic $P$. aeruginosa infection status independent of any other pathogens detectable in CF airway fluids. The scatter graph depicts individual patients with horizontal bars indicating the median for each group. 
TABLE 2 CCL18 levels and CF pathogens

\begin{tabular}{lcc} 
& \multicolumn{2}{c}{ p-value $^{\#}$} \\
\cline { 2 - 3 } & CCL18 serum & CCL18 sputum \\
\hline Pseudomonas aeruginosa & $<0.05$ & $<0.05$ \\
Staphylococcus aureus (MSSA) & 0.21 & 0.17 \\
Haemophilus influenzae & 0.28 & 0.24 \\
Achromobacter xylosoxidans & 0.32 & 0.35 \\
Stenotrophomonas maltophilia & 0.18 & 0.25 \\
Aspergillus fumigatus & 0.13 & 0.16 \\
Candida albicans & 0.29 & 0.34
\end{tabular}

CF: cystic fibrosis; MSSA: methicillin-sensitive S. aureus. Bold font indicates statistical significance. ${ }^{\text {\#: }}$ twotailed p-values for the correlations (Spearman's rho) between detection of the indicated bacteria/fungi in CF airway fluids and CCL18 protein levels in serum and sputum from CF patients.

statistically significant correlation with CCL18 protein levels, suggesting an interaction of CCL18 with CXCR1, but not CXCR2, recruitment pathways.

\section{Discussion}

CF lung disease is characterised by a progressive destruction of the lung tissue due to bacterial infection, chronic inflammation and tissue remodelling. Besides elastase [31], immunological host factors responsible for determining the severity of the pulmonary disease, which may serve as biomarkers, are poorly defined. Here we show that the chemokine CCL18 is increased in CF patients, both systemically and at the pulmonary site of inflammation. Our studies further showed that CCL18 protein levels characterise chronic $P$. aeruginosa infections in CF and correlate with both pulmonary function parameters and neutrophilattracting chemokines. When viewed in combination, these studies suggest that CCL18 may serve as a novel biomarker and potential therapeutic target in CF lung disease.

CCL18 is preferentially expressed in the lung and has been found to be increased in a variety of pulmonary diseases, including hypersensitivity pneumonitis [16], IPF [17], sarcoidosis [21], allergic asthma [7, 22], various interstitial lung diseases [32] and lung disease in systemic sclerosis [33]. In IPF, a vicious circle involving alveolar macrophages and fibroblasts was found to perpetuate pulmonary fibrosis via CCL18 [34]. CCL18 protein levels were further shown to correlate with mortality in IPF [17]. In COPD, increased CCL18 levels in serum were associated with an unfavourable clinical course [18], acute exacerbations [20]
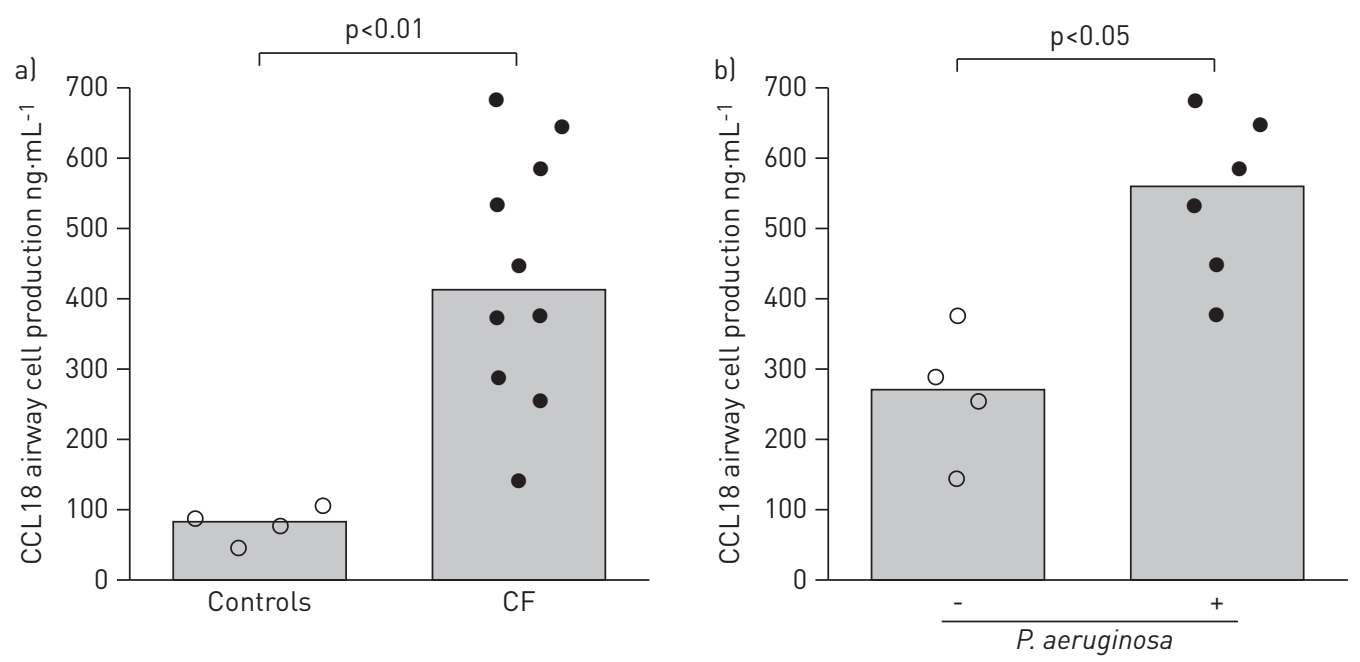

FIGURE 3 Ex vivo CCL18 production. CCL18 protein levels in supernatants were quantified by means of ELISA after overnight incubation of a) airway (sputum) cells isolated from CF patients $(n=10)$ and healthy controls $(n=4)$; or $b) C F$ patients with $(+; \mathrm{n}=6)$ or without $(-; \mathrm{n}=4)$ chronic Pseudomonas aeruginosa infection. The scatter graphs depict individual patients and bars depict the medians. 

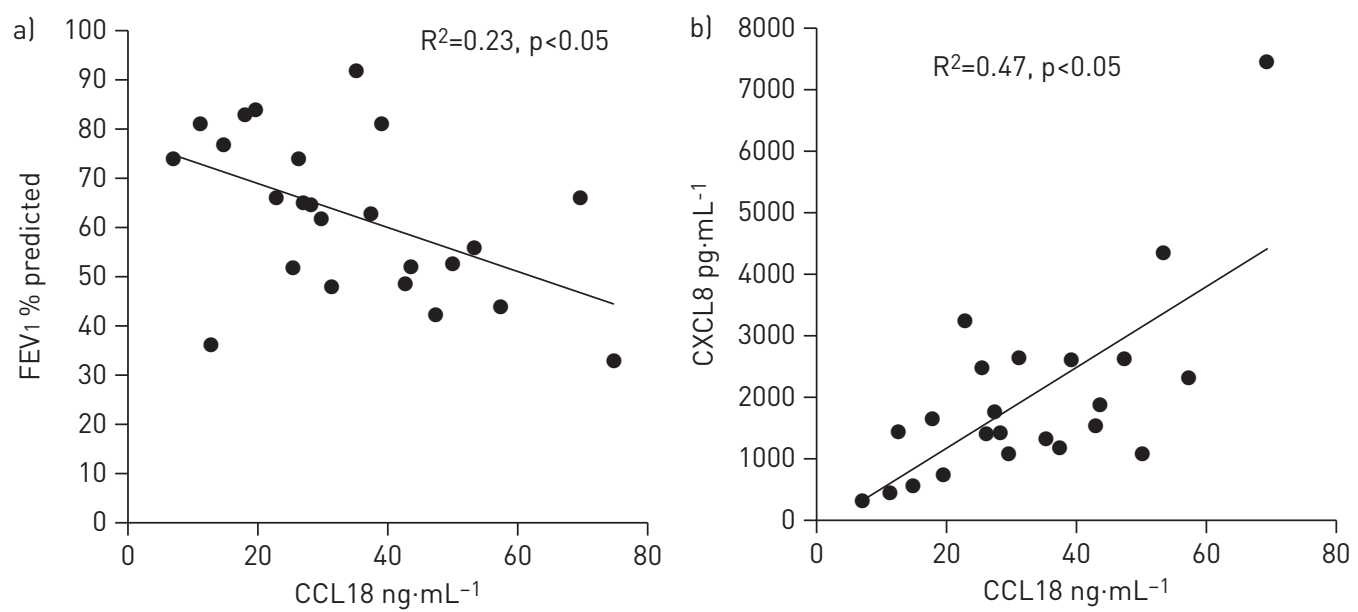

FIGURE 4 Correlation of sputum CCL18 levels with lung function and CXCL8. a) Correlation of CCL18 protein levels, quantified by ELISA, in sputum from cystic fibrosis (CF) patients with forced expiratory volume in $1 \mathrm{~s}(\mathrm{FEV} 1) \%$ predicted. b) Correlation between CCL18 and CXCL8 protein levels, quantified by ELISA, in sputum from CF patients.

and overall mortality [19]. In asthma, CCL18 levels were elevated in sputum, but not in serum [35], which contrasts with findings in IPF and COPD, probably due to the underlying different disease entities. In other studies, CCL18 has been demonstrated to predict the risk of cardiovascular events [36].

CCL18 protein levels were consistently higher in the circulation compared with the airway compartment in our study. Beyond CF lung disease, this airway-to-blood compartmentalisation seems to be a general phenomenon of CCL18 biological distribution, since similar CCL18 protein distributions have been found previously in interstitial lung diseases [32] and asthma [35]. Nevertheless, the mechanisms regulating the biological distribution of CCL18 in CF and other pulmonary diseases remain poorly understood and should be dissected in future investigations. However, the lack of a rodent homologue for human CCL18 precludes in vivo studies in small animal models.

Based on our observation that CCL18 levels were increased systemically as well as in the airway fluids, we speculate that both systemic CFTR-associated and pulmonary infection-associated factors modulate the production of CCL18 in CF patients. Regarding the cellular source of CCL18, increased serum levels may result from leakage of pulmonary CCL18 into the circulation and/or from a systemic leukocyte Th2/ alternative macrophage (M2) activation and/or neutrophil polarisation in CF [37, 38], meaning that circulating leukocytes in CF could be intrinsically polarised towards increased CCL18 production. The latter hypothesis is supported by our observation that CCL18 levels were higher in the circulation than in the airway compartment in CF and by a previous study showing that CCL18 expression was systemically increased in circulating blood neutrophils of CF patients [23]. Based on the latter study, we hypothesise that CFTR deficiency may exert either a direct effect on the gene expression pattern of neutrophils or that the altered gene expression pattern of neutrophils might be a secondary response to the continuous inflammatory process in CF ("inflammatory priming") [23]. CCL18 expression has been found to be increased in the peripheral blood mononuclear cells of patients with asthma [22], which supports the CFTR-independent, systemic inflammatory priming hypothesis. However, 1) the correlation of airway, but not serum, CCL18 levels with lung function in our study, 2) the association of chronic P. aeruginosa airway infection with CCL18 levels and 3) the lack of an association of plasma CCL18 levels with hospitalisation in $\mathrm{CF}$ in a previous study [39] clearly also point towards a major impact of pulmonary infection on CCL18 airway levels in CF patients.

The function of CCL18 remains poorly understood and there is only limited evidence linking CCL18 with disease mechanisms. CCL18 was found to stimulate collagen production by lung fibroblasts and thereby interact in a positive feedback loop between alveolar macrophages and lung fibroblasts [34]. Furthermore, CCL18 is known as a marker for alternative macrophage (M2) activation [11], a phenotype essentially involved in allergy, tissue repair, fibrosis and cancer immune evasion. Accordingly, CCL18 has been found to induce epithelial to mesenchymal transition in lung cancer cells and to elevate their invasive potential [40]. Alternative macrophage activation is mainly mediated by the Th2 cytokine IL-4, while the antiinflammatory cytokine IL-10 was found to further enhance IL-4-induced CCL18 expression [41]. Recently, alternative M2 macrophage activation has been demonstrated in the CF lung and shown to correlate with a decrease in pulmonary function [42]. However, studies on M1/M2 macrophage polarisation in murine and 
human CF remain controversial [38] and further comparative investigations are required to define the macrophage phenotype in CF and its relationship to CCL18 production. Since chronic P. aeruginosa infection has been linked to a Th2 polarisation in CF patients [43], Pseudomonas-induced Th2/M2 priming could enhance CCL18 levels in CF patients, although this is an issue requiring further studies.

Beyond $P$. aeruginosa, our CF patient cohort was characterised by a poly-microbial colonisation/infection pattern, which is typical for adolescent and adult CF patients. However, P. aeruginosa was the only pathogen that was statistically associated with CCL18 protein levels in our CF patients. Despite these intriguing putative links between CF, $P$. aeruginosa, Th2/M2 and CCL18, further conclusions should be drawn only in the context of the inherent limitations of this study, which are 1) the size of the included CF population, 2) the missing mechanism(s) underlying the increased CCL18 levels in P. aeruginosa-infected CF patients, 3) the lack of longitudinal data on CCL18 levels in young CF patients before and during $P$. aeruginosa acquisition and 4) the unresolved question of how CFTR could influence CCL18 systemically in CF. These are issues that should be addressed in future studies.

Collectively, the present study demonstrates that the chemokine CCL18 is increased in CF patients, both systemically and in the airways, characterises chronic P. aeruginosa infection and correlates with lung function and neutrophilic chemokines. Inspired by this study, future investigations are warranted to assess whether CCL18 may serve as a novel biomarker and potential therapeutic target in CF lung disease.

\section{References}

Davis PB, Drumm M, Konstan MW. Cystic fibrosis. Am J Respir Crit Care Med 1996; 154: 1229-1256.

Ratjen FA. Cystic fibrosis: pathogenesis and future treatment strategies. Respir Care 2009; 54: 595-605.

Gerard C, Rollins BJ. Chemokines and disease. Nat Immunol 2001; 2: 108-115.

Sabroe I, Lloyd CM, Whyte MK, et al. Chemokines, innate and adaptive immunity, and respiratory disease. Eur Respir J 2002; 19: 350-355.

Prasse A, Müller-Quernheim J. Non-invasive biomarkers in pulmonary fibrosis. Respirology 2009; 14: 788-795.

Kelly E, Owen CA, Pinto-Plata V, et al. The role of systemic inflammatory biomarkers to predict mortality in chronic obstructive pulmonary disease. Expert Rev Respir Med 2013; 7: 57-64.

7 Tsicopoulos A, Chang Y, Ait Yahia S, et al. Role of CCL18 in asthma and lung immunity. Clin Exp Allergy 2013; 43: 716-722.

8 Pochetuhen K, Luzina IG, Lockatell V, et al. Complex regulation of pulmonary inflammation and fibrosis by CCL18. Am J Pathol 2007; 171: 428-437.

9 Schutyser E, Richmond A, Van Damme J. Involvement of CC chemokine ligand 18 (CCL18) in normal and pathological processes. J Leukoc Biol 2005; 78: 14-26.

10 Hieshima K, Imai T, Baba M, et al. A novel human CC chemokine PARC that is most homologous to macrophageinflammatory protein-1 $\alpha / \mathrm{LD} 78 \alpha$ and chemotactic for T lymphocytes, but not for monocytes. J Immunol 1997; 159: 1140-1149.

11 Kodelja V, Müller C, Politz O, et al. Alternative macrophage activation-associated CC-chemokine-1, a novel structural homologue of macrophage inflammatory protein-1 $\alpha$ with a Th2-associated expression pattern. J Immunol 1998; 160: 1411-1418.

12 Bellinghausen I, Reuter S, Martin H, et al. Enhanced production of CCL18 by tolerogenic dendritic cells is associated with inhibition of allergic airway reactivity. J Allergy Clin Immunol 2012; 130: 1384-1393.

13 Atamas SP, Luzina IG, Choi J, et al. Pulmonary and activation-regulated chemokine stimulates collagen production in lung fibroblasts. Am J Respir Cell Mol Biol 2003; 29: 743-749.

14 Schutyser E, Struyf S, Proost P, et al. Identification of biologically active chemokine isoforms from ascitic fluid and elevated levels of CCL18/pulmonary and activation-regulated chemokine in ovarian carcinoma. J Biol Chem 2002; 277: 24584-24593.

15 Struyf S, Schutyser E, Gouwy M, et al. PARC/CCL18 is a plasma CC chemokine with increased levels in childhood acute lymphoblastic leukemia. Am J Pathol 2003; 163: 2065-2075.

16 Pardo A, Smith KM, Abrams J, et al. CCL18/DC-CK-1/PARC up-regulation in hypersensitivity pneumonitis. J Leukoc Biol 2001; 70: 610-616.

17 Prasse A, Probst C, Bargagli E, et al. Serum CC-chemokine ligand 18 concentration predicts outcome in idiopathic pulmonary fibrosis. Am J Respir Crit Care Med 2009; 179: 717-723.

18 Pinto-Plata V, Toso J, Lee K, et al. Profiling serum biomarkers in patients with COPD: associations with clinical parameters. Thorax 2007; 62: 595-601.

19 Sin DD, Miller BE, Duvoix A, et al. Serum PARC/CCL-18 concentrations and health outcomes in chronic obstructive pulmonary disease. Am J Respir Crit Care Med 2011; 183: 1187-1192.

20 Hurst JR, Donaldson GC, Perera WR, et al. Use of plasma biomarkers at exacerbation of chronic obstructive pulmonary disease. Am J Respir Crit Care Med 2006; 174: 867-874.

21 Mrazek F, Sekerova V, Drabek J, et al. Expression of the chemokine PARC mRNA in bronchoalveolar cells of patients with sarcoidosis. Immunol Lett 2002; 84: 17-22.

22 de Nadaï P, Charbonnier AS, Chenivesse C, et al. Involvement of CCL18 in allergic asthma. J Immunol 2006; 176: 6286-6293.

23 Adib-Conquy M, Pedron T, Petit-Bertron AF, et al. Neutrophils in cystic fibrosis display a distinct gene expression pattern. Mol Med 2008; 14: 36-44.

24 Hafen GM, Hartl D, Regamey N, et al. Allergic bronchopulmonary aspergillosis: the hunt for a diagnostic serological marker in cystic fibrosis patients. Expert Rev Mol Diagn 2009; 9: 157-164.

25 Hartl D, Latzin P, Zissel G, et al. Chemokines indicate allergic bronchopulmonary aspergillosis in patients with cystic fibrosis. Am J Respir Crit Care Med 2006; 173: 1370-1376. 
Latzin P, Hartl D, Regamey N, et al. Comparison of serum markers for allergic bronchopulmonary aspergillosis in cystic fibrosis. Eur Respir J 2008; 31: 36-42.

Hartl D, Latzin P, Hordijk P, et al. Cleavage of CXCR1 on neutrophils disables bacterial killing in cystic fibrosis lung disease. Nat Med 2007; 13: 1423-1430.

Koller B, Kappler M, Latzin P, et al. TLR expression on neutrophils at the pulmonary site of infection: TLR1/TLR2mediated up-regulation of TLR5 expression in cystic fibrosis lung disease. J Immunol 2008; 181: 2753-2763.

Hector A, Jonas F, Kappler M, et al. Novel method to process cystic fibrosis sputum for determination of oxidative state. Respiration 2010; 80: 393-400.

Hartl D, Krauss-Etschmann S, Koller B, et al. Infiltrated neutrophils acquire novel chemokine receptor expression and chemokine responsiveness in chronic inflammatory lung diseases. J Immunol 2008; 181: 8053-8067. Sly PD, Gangell CL, Chen L, et al. Risk factors for bronchiectasis in children with cystic fibrosis. N Engl J Med 2013; 368: 1963-1970.

Cai M, Bonella F, He X, et al. CCL18 in serum, BAL fluid and alveolar macrophage culture supernatant in interstitial lung diseases. Respir Med 2013; 107: 1444-1452.

Tiev KP, Hua-Huy T, Kettaneh A, et al. Serum CC chemokine ligand-18 predicts lung disease worsening in systemic sclerosis. Eur Respir J 2011; 38: 1355-1360.

Prasse A, Pechkovsky DV, Toews GB, et al. A vicious circle of alveolar macrophages and fibroblasts perpetuates pulmonary fibrosis via CCL18. Am J Respir Crit Care Med 2006; 173: 781-792.

Kim HB, Kim CK, Iijima K, et al. Protein microarray analysis in patients with asthma: elevation of the chemokine PARC/CCL18 in sputum. Chest 2009; 135: 295-302.

Kraaijeveld AO, de Jager SC, de Jager WJ, et al. CC chemokine ligand-5 (CCL5/RANTES) and CC chemokine ligand-18 (CCL18/PARC) are specific markers of refractory unstable angina pectoris and are transiently raised during severe ischemic symptoms. Circulation 2007; 116: 1931-1941.

Hartl D. Immunological mechanisms behind the cystic fibrosis-ABPA link. Med Mycol 2009; 47: Suppl. 1, S183-S191. Hartl D, Gaggar A, Bruscia E, et al. Innate immunity in cystic fibrosis lung disease. J Cyst Fibros 2012; 11: 363-382. Ngan DA, Wilcox PG, Aldaabil M, et al. The relationship of systemic inflammation to prior hospitalization in adult patients with cystic fibrosis. BMC Pulm Med 2012; 12: 3.

Ploenes T, Scholtes B, Krohn A, et al. CC-chemokine ligand 18 induces epithelial to mesenchymal transition in lung cancer A549 cells and elevates the invasive potential. PLoS One 2013; 8: e53068.

Pechkovsky DV, Prasse A, Kollert F, et al. Alternatively activated alveolar macrophages in pulmonary fibrosismediator production and intracellular signal transduction. Clin Immunol 2010; 137: 89-101.

Murphy BS, Bush HM, Sundareshan V, et al. Characterization of macrophage activation states in patients with cystic fibrosis. J Cyst Fibros 2010; 9: 314-322.

Hartl D, Griese M, Kappler M, et al. Pulmonary T(H)2 response in Pseudomonas aeruginosa-infected patients with cystic fibrosis. J Allergy Clin Immunol 2006; 117: 204-211. 